\title{
E109K Is a SEC23B Founder Mutation among Israeli Moroccan Jewish Patients with Congenital Dyserythropoietic Anemia Type II
}

\author{
Achiya Amir ${ }^{a}$ Orly Dgany ${ }^{c}$ Tanya Krasnov ${ }^{c}$ Peretz Resnitzky ${ }^{e}$ \\ Ronit Mor-Cohen ${ }^{d}$ Michael Bennett ${ }^{g} \quad$ Alain Berrebi $^{f} \quad$ Hannah Tamary $^{b, c}$ \\ a Department of Pediatrics B, b Pediatric Hematology/Oncology Division, Schneider Children's Medical Center of \\ Israel, and Sackler Faculty of Medicine, Tel Aviv University, 'Pediatric Hematology Laboratory, Felsenstein Medical \\ Research Center, Beilinson Campus, Petah Tikva, Sackler Faculty of Medicine, Tel Aviv University, and dAmalia Biron \\ Research Institute of Thrombosis and Hemostasis, Chaim Sheba Medical Center, Tel Hashomer, and the

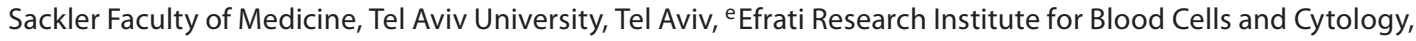 \\ Kaplan Hospital, and f Department of Hematology, Kaplan Hospital, Rehovot, and 9 Department of Hematology, \\ Ha'Emek Medical Center, Afula, Israel
}

\section{Key Words}

Congenital dyserythropoietic anemia II $\cdot$ Moroccan Jews

SEC23B gene

\begin{abstract}
Objective: Congenital dyserythropoietic anemia (CDA) is characterized by ineffective erythropoiesis, binuclearity of erythroid precursors and secondary hemochromatosis. Recently, the gene mutated in CDA type II (CDA II), SEC23B, was identified. All Israeli patients with CDA II are of North African (mainly Moroccan) Jewish descent. We investigated the molecular basis of CDA II in those patients. Methods: Participants included 11 patients with CDA II from 8 apparently unrelated families. Clinical data were retrieved from medical files, and blood was collected for DNA analysis. Results: The majority of patients (10/11) were homozygous for a common SEC23B mutation (E109K). Haplotype analysis revealed a common genetic background in all patients. One patient was a compound heterozygote for the E109K mutation and a novel mutation, T710M. All patients were transfusion independent, with increasing iron overload with age. We estimate the E109K mutation to be 2,400 years old, in line with
\end{abstract}

Jewish migration history. Conclusions: Most CDA II patients in Israel are of Moroccan Jewish origin and carry a common SEC23B mutation, E109K, the first to be described as a founder mutation causing CDA II. As previously suggested, carrying 2 missense mutations is associated with a relatively nonsevere phenotype.

Copyright $\odot 2011$ S. Karger AG, Basel

\section{Introduction}

Congenital dyserythropoietic anemias (CDAs) are a group of red blood cell (RBC) disorders characterized by ineffective erythropoiesis, pathognomonic cytopathology of the nucleated $\mathrm{RBC}$ precursors in the bone marrow and secondary hemochromatosis. Based on bone marrow morphological features, Heimpel and Wendt [1] in 1968 classified these disorders into 3 subtypes (CDA I-III), a classification which is still valid today with the identification of mutations in distinct genes for CDA type I (CDAN1) [2] and type II (SEC23B) [3, 4]. The CDA III gene has been mapped in one family to chromosome 15q21, but has not been cloned yet [5].

\section{KARGER}

Fax +41613061234 E-Mail karger@karger.ch www.karger.com
(C) 2011 S. Karger AG, Basel

$0001-5792 / 11 / 1254-0202 \$ 38.00 / 0$

Accessible online at:

www.karger.com/aha
Prof. Hannah Tamary

Hematology Unit, Schneider Children's Medical Center of Israel

14 Kaplan Street

Petah Tikva 49202 (Israel)

Tel. +972 3925 3669, Fax +972 3925 3042, E-Mail htamary@post.tau.ac.il 
CDA II, known also as hereditary erythroblastic multinuclearity with a positive acidified serum test [6], is the most common type of CDA, with an estimated annual incidence of 1 in 100,000 live births [7]. The disease is inherited in an autosomal recessive manner. The major diagnostic morphological abnormality in bone marrow is binuclearity of $10-50 \%$ of the mature erythroblasts [8]. Additional diagnostic criteria include bone marrow electron microscopy with the presence of a double membrane, running internally to the erythroblast cellular membrane, and a narrow and fast migrating band 3 on $\mathrm{RBC}$ membrane protein electrophoresis using SDS-PAGE [8]. Red cells of patients with CDA II also retain a very high agglutinability by anti-i sera throughout life.

Recently, Schwarz et al. [3] found that the SEC23B gene is mutated in CDA II patients. SEC23B encodes a member of the cytoplasmic coat proteins, which are involved in the intracellular secretory pathway. The gene has $20 \mathrm{ex}-$ ons, including a pretranslational region. Until recently, the encoded protein was only known to be essential for chondrocyte activity and craniofacial skeletal development; when mutated in animal models, it was shown to cause skeletal abnormalities and facial dysmorphisms [9]. Studying the SEC23B gene in CDA II patients yielded identification of more than 30 disease-causing mutations of SEC23B, with 2 hot spots [325G $>$ A (E109K) and 40C $>$ T (R14W), found in 30 and 15\% of affected alleles, respectively] $[3,4,10]$. The existence of a founder effect was not identified.

In Israel, all known patients diagnosed with CDA II to date are of North African descent, mainly Moroccan Jews $[11,12]$. The aim of the present study was to determine the molecular basis of CDA II in known Israeli patients.

\section{Patients and Methods}

\section{Patients}

Participants included 11 CDA II patients from 8 apparently unrelated families (families A-H; fig. 1). Eight patients were diagnosed and followed at the Institute of Hematology, Kaplan Medical Center, Rehovot, and 3 at the Ha'Emek Medical Center, Afula, Israel. The medical charts were reviewed for means of diagnosis, clinical presentation, secondary complications and treatment. For each patient, we recorded the mean of the available values of hemoglobin and mean corpuscular volume, as well as the maximum serum ferritin levels. After signed informed consent was obtained from the patient, blood was drawn for DNA analysis. Two additional family members (B9 and G6; fig. 1) were clinically diagnosed as patients but were not available for DNA analysis.

\section{DNA Isolation and Amplification}

Genomic DNA was isolated from the white blood cells using a DNA isolation kit for mammalian blood (Roche Diagnostics, Mannheim, Germany). Each of the 19 SEC23B exons and pretranslational zone [transcript variant ENST00000377475 of Ensembl Genome Browser (http://www.ensembl.org/Homo_sapiens/Info/Index)], including exon-intron boundaries, was amplified by a DNA T3 Thermocycler (Biometra, Göttingen, Germany) in a 50- $\mu$ l aliquot containing 100-200 ng of genomic DNA. Primers are available upon request (odgani@post.tau.ac.il).

\section{DNA Sequencing}

Amplification products were purified and sequenced using the BigDye terminator version 1.1 Cycle Sequencing Kit (Applied Biosystems, ABI, Foster City, Calif., USA) on the ABI Prism 3730xl DNA Analyzer with DNA Sequencing Analysis Software version 5.2. Nucleotide positions were numbered according to accession number NM_006363. Amino acids were assigned according to NP_006354.

\section{Restriction Enzyme Detection}

As neither of the mutations detected (see Results) contained a known altered restriction site, we deliberately introduced a mismatch in one of the primers in the polymerase chain reaction (PCR) tests so that restriction sites would be introduced into the mutant allele after amplification, as follows: a BstBI restriction site flanking the c.325G $>$ A mutation and a Bst NI restriction site flanking c.2129C $>$ T. Mutant alleles were identified by sizing the digested PCR products. In this manner, we were able to easily screen chromosomes of healthy subjects for each mutation.

\section{Haplotype Mapping}

Families A-H were genotyped using 6 polymorphic markers, located in regions 20p11.23-20p12.1 of chromosome 20, in the vicinity of $S E C 23 B$. All had more than 4 potential alleles, with a heterogeneity index of 0.44-0.87. Six markers, D20S114, D20S112, D20S182, D20S475, D20S860 and D20S54, were derived from the UniSTS database (http://genecards.weizmann.ac.il/geneloc/index.shtml; fig. 2). Two additional single-nucleotide polymorphic markers were located within the defined SEC23B gene (HapMap database), i.e. reference SNP rs1205200, with 0.43 average heterozygosity, and reference SNP rs6081183, with 0.48 average heterozygosity (http://www.ncbi.nlm.nih.gov/projects/SNP/). The sizes of the PCR products were compared between affected and nonaffected members of the 8 families using a 5-15\% PAGE gradient. The 8 markers tested made it possible to define the smallest cosegregated haplotype.

\section{Mutation Age Estimation}

The DMLE+ 2.0 software program (www.dmle.org) was designed for high-resolution mapping of disease mutations and for estimating the age of mutations (by Bayesian statistics, using the software's Markov chain Monte Carlo algorithm). Age is estimated according to the observed linkage disequilibrium between the mutation and linked polymorphic markers flanking it in DNA samples from unrelated affected and nonaffected individuals [13, 14]. In the present study, the estimated age of the mutation was based on the following parameters: haplotype mapping of the patients, as described above, compared to 26 healthy Moroccan Jewish controls; chromosomal map distances between markers and 


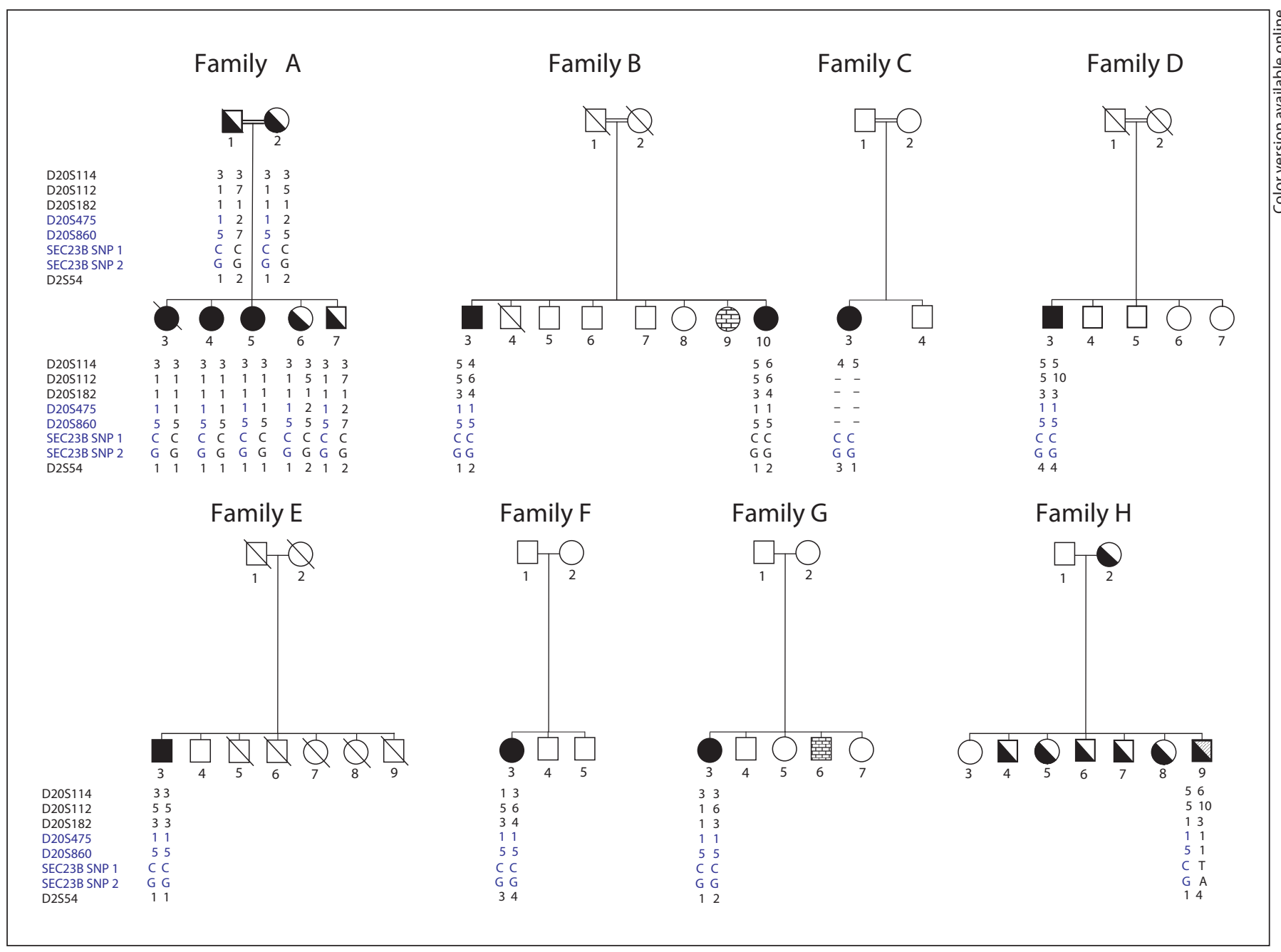

Fig. 1. Pedigree and haplotypes of families with CDA II. Solid symbols represent homozygotes for the E109K mutation; half-solid symbols represent heterozygotes for the same mutation; the half-hatched symbol represents the T710M mutation, and the bricked symbols represent subjects clinically presumed to be patients but without DNA analysis. SNP1 = Reference SNP rs1205200; SNP2 = reference SNP rs6081183. When available, the haplotype for chromosome 20 markers is shown below each family member.

Fig. 2. Genetic markers flanking the SEC23B gene.

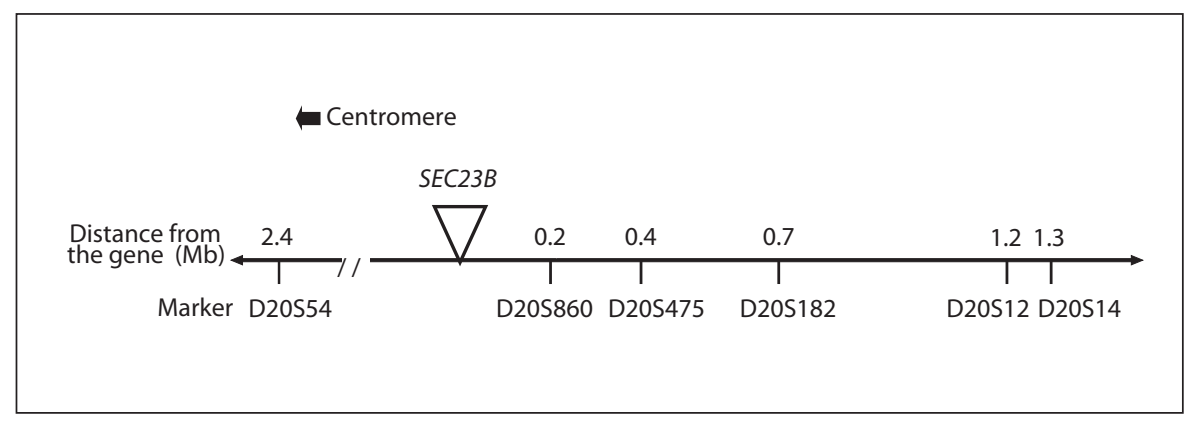


Table 1. Ethnic and clinical background of 11 CDA II patients

\begin{tabular}{|c|c|c|c|c|c|c|c|c|c|c|c|c|}
\hline $\begin{array}{l}\text { Family/ } \\
\text { patient No./ } \\
\text { gender }\end{array}$ & Ethnicity & $\begin{array}{l}\text { Age } \\
\text { years }\end{array}$ & $\begin{array}{l}\text { Age at } \\
\text { diag- } \\
\text { nosis } \\
\text { years }\end{array}$ & $\begin{array}{l}\text { Presence } \\
\text { of } i \\
\text { antigen }\end{array}$ & $\begin{array}{l}\text { Ham } \\
\text { test }\end{array}$ & $\begin{array}{l}\text { Diagnosis } \\
\text { of bone } \\
\text { marrow }\end{array}$ & $\begin{array}{l}\text { Mean } \mathrm{Hb} \\
\mathrm{g} / \mathrm{dl}\end{array}$ & $\begin{array}{l}\text { Mean } \\
\text { MCV }\end{array}$ & $\begin{array}{l}\text { Neonatal } \\
\text { or child- } \\
\text { hood } \\
\text { jaundice }\end{array}$ & $\begin{array}{l}\text { Hepatomegaly/ } \\
\text { splenomegaly/ } \\
\text { cholelithiasis }\end{array}$ & $\begin{array}{l}\text { Age at sple- } \\
\text { nectomy and } \\
\text { cholecystec- } \\
\text { tomy, years }\end{array}$ & $\begin{array}{l}\text { Maximal ferritin } \\
\text { levels, ng/ml/ } \\
\text { evidence of } \\
\text { hemochromatosis }\end{array}$ \\
\hline $\mathrm{A} / 3 / \mathrm{F}$ & MJ & NA & NA & NA & + & NA & NA & NA & NA & NA & NA & NA \\
\hline $\mathrm{A} / 4 / \mathrm{F}$ & MJ & 33 & 2 & yes & + & LM & 9 & 95 & yes & $+/+/+$ & 22 & 330 \\
\hline $\mathrm{A} / 5 / \mathrm{F}$ & MJ & 31 & 3 months & yes & + & LM & 11.1 & 90 & yes & $-1+/+$ & 23 & $122 /$ no \\
\hline $\mathrm{B} / 3 / \mathrm{M}$ & $\mathrm{MJ}$ & 62 & 18 & NA & - & LM, EM & 11.5 & 95 & yes & $+/+/+$ & 51 & 3,500/DM, ELE \\
\hline $\mathrm{B} / 10 / \mathrm{F}$ & MJ & 49 & 13 & NA & NA & LM & 12.2 & 94 & no & $+/+/+$ & 40 & $2,183 /$ no \\
\hline $\mathrm{C} / 3 / \mathrm{F}$ & MJ & 64 & 28 & NA & + & LM & 11 & 99 & yes & $+/+/+$ & 29 & 90/no \\
\hline $\mathrm{D} / 3 / \mathrm{M}$ & MJ & 53 & 47 & NA & + & LM & 11.3 & 100 & no & $-1+/+$ & 47 & $436 /$ no \\
\hline $\mathrm{E} / 3 / \mathrm{M}$ & MJ & 60 & 44 & yes & - & LM, EM & 10.4 & 95 & yes & $+/+/-$ & not done & $\begin{array}{l}\text { 1,134/DM, } \\
\text { hypothyroidism }\end{array}$ \\
\hline $\bar{F} / 3 / \mathrm{F}$ & MAJ & 34 & 30 & NA & + & LM, EM & 11 & 84 & yes & $-1+1-$ & not done & 292/no \\
\hline $\mathrm{G} / 3 / \mathrm{F}$ & $\mathrm{MJ}$ & 50 & 14 & yes & + & LM & 9.6 & NA & yes & $+/+/+$ & 15 & NA \\
\hline $\mathrm{H} / 9 / \mathrm{M}$ & MJ & 46 & 25 & yes & + & LM, EM & 10.1 & 103 & yes & $+/+/-$ & 26 & $1,263 /$ no \\
\hline$\overline{M e a n} \pm$ SD & & $48 \pm 11.6$ & $22 \pm 15$ & & & & $10.7 \pm 0.9$ & $95 \pm 5.3$ & & & & $1,039 \pm 1,085$ \\
\hline $\begin{array}{l}\text { Normal } \\
\text { values }\end{array}$ & & & & & & & $\begin{array}{l}\text { M: } 13-15 \\
\text { F: } 12-14\end{array}$ & $78-90 \mathrm{fl}$ & & & & $\begin{array}{l}\text { M: } 25-250 \\
\text { F: } 10-130\end{array}$ \\
\hline
\end{tabular}

$\mathrm{MCV}=$ Mean corpuscular volume; $\mathrm{MJ}=$ Moroccan Jewish origin; MAJ = Moroccan-Algerian Jewish origin; $\mathrm{LM}=$ light microscopy; EM = electron microscopy; $\mathrm{DM}=$ diabetes mellitus; $\mathrm{ELE}=$ elevated liver enzymes; $\mathrm{NA}=$ not available.

the position of the mutation relative to the markers, derived from the human genome working draft, and the reported estimated population growth rate of 0.03 in the Moroccan Jewish community [15].

\section{Statistics}

Comparison of the common haplotype carriage frequency between the homozygote patient group and the healthy control group was done using a $\chi^{2}$ test.

\section{Results}

\section{Clinical Data}

Table 1 summarizes the ethnic background, clinical data and mode of diagnosis of the 11 patients. Clinical data for 1 patient (A3; fig. 1), who died of breast cancer, are missing. Three patients were members of one family (family A 3/4/5; fig. 1), and 2 patients were members of another (family B $3 / 10$; fig. 1); the remaining patients were from apparently unrelated families. Ten patients were of Moroccan Jewish descent and 1 patient was of Moroccan-Algerian Jewish descent (F/3; fig. 1).

In these patients, anemia was in general mild to moderate, with a mean hemoglobin level of $10.7 \mathrm{~g} / \mathrm{dl}$ (range 9-12.2 g/dl). Mean corpuscular volumes were high, ranging from 90 to $103 \mathrm{fl}$. All 11 patients had splenomegaly, and 7 had hepatomegaly as well. Seven patients had cholelithiasis. Eight had undergone either cholecystectomy and splenectomy $(n=7)$ or cholecystectomy alone $(n=1)$. Serum ferritin levels ranged from 120 to $3,500 \mathrm{ng} / \mathrm{ml}$. Two patients had evidence of hemochromatosis (elevated liver enzymes in 1 patient, hypothyroidism in the other patient and diabetes mellitus in both). Three patients (A/5, F/3, H/9; fig. 1) had received blood on one occasion, for severe anemia during the neonatal period (in 1) or hemoglobin decrease due to an intercurrent infectious disease (in 2). None of the patients was blood transfusion dependent. Three patients were occasionally treated with deferoxamine $(\mathrm{B} / 3, \mathrm{~B} / 10, \mathrm{H} / 9$; table 1$)$.

The disease was diagnosed when the patients were between 3 months and 47 years of age. Nine patients had jaundice as neonates, retrospectively consistent with the first manifestation of the disease. It is noteworthy that second and third cases within the same family were diagnosed substantially earlier in the course of the disease. The Ham test, performed in 10 patients, was positive in 8 . In all cases, the final diagnosis was based on light microscopy examination of bone marrow aspirate; in 4 patients, the bone marrow was also examined by electron microscopy.

Of note, patient E/3 (fig. 1) has syndactyly of all fingers and toes in all of his hands and feet; this was not found in any of the remaining 10 patients. 


\section{SEC23B Mutations}

Ten of the 11 patients, from families A-G (fig. 1), were found to be homozygous for a single, previously described, missense mutation, c.325G $>\mathrm{A}$ in exon $4[3,4]$. The mutation results in a substitution of noncharged glutamic acid at position 109 with charged lysine (p.Glu109Lys, E109K). By deliberately introducing a restriction enzyme site during screening, as described above, we were able to detect 1 positive allele among 204 alleles from healthy Moroccan Jewish subjects (0.49\%).

One patient (H/9; fig. 1) was found to be a compound heterozygote for the E109K mutation in exon 4 and a novel missense mutation, c.2129C $>\mathrm{T}$ in exon 18. This patient was of Moroccan Jewish descent and had neither a unique presentation nor a distinctive clinical course. This novel mutation results in the substitution of threonine with methionine (p.Thr710Met, T710M). The mutation was screened by a deliberately introduced restriction enzyme site and was not detected among 214 alleles from healthy Moroccan Jewish subjects.

\section{Haplotype Analysis}

Our finding that 10 of the 11 patients had the same ethnic background and shared the same mutation suggested a founder haplotype. Using the polymorphic markers described in Patients and Methods, we found that all CDA II haplotypes with the E109K mutation were identical, i.e. 1-5-C-G (fig. 1). The eleventh patient, found to be a compound heterozygote for E109K and T710M, carried the common haplotype as well as a different one (H/9; fig. 1). Analysis of the polymorphic marker distribution among 52 chromosomes from unrelated healthy subjects of Moroccan Jewish descent revealed potential carriage of the founder haplotype in only 16 alleles (31\%), compared to 21 out of $22(95.5 \%)$ of the CDA II patients' chromosomes carrying the E109K mutation $(\mathrm{p}=1.2 \times$ $\left.10^{-9}\right)$.

\section{Age Estimation of the SEC23B c.325G $>$ A Mutation}

The DMLE+ 2.0 program was used to estimate the age of the E109K mutation among Moroccan Jews using the haplotype map of the homozygous patients and 26 unrelated healthy Moroccan Jewish subjects. The mutation densities peaked at 118 generations. Assuming that a generation is equivalent to 20 years, the age of the mutation is about 2,400 years.

\section{Discussion}

CDAs are a group of rare inherited disorders characterized by anemia, ineffective erythropoiesis and secondary hemochromatosis [1]. CDA II constitutes the most common subtype. Diagnosis of CDA II is based on the presence of congenital anemia, evidence of ineffective erythropoiesis and at least $10 \%$ binuclearity of bone marrow erythroblasts, supported also by either a positive acid lysis test, abnormality of bands 3 and 4.5 in SDS-PAGE $\mathrm{RBC}$ membrane electrophoresis or the presence of a double membrane in RBC precursors on bone marrow electron microscopy. Recently, with the identification of $S E C 23 B$ as the gene mutated in this disease, a new major diagnostic tool has emerged.

We investigated SEC23B mutations in 11 Israeli patients previously diagnosed with CDA II. The diagnosis of CDA II was based on the presence of anemia and splenomegaly, supported by a positive Ham test (in 8 out of 10 patients; table 1), and the presence of $i$ antigen (in 5 out of 5 patients; table 1). All had more than $10 \%$ binuclear erythroid precursors, whereas positive bone marrow electron microscopy findings were present in all 4 patients investigated. It was previously noted that the vast majority of Israeli patients with CDA II were of Moroccan Jewish descent.

We were able to identify SEC23B mutations in all patients. Not surprisingly in light of the patients' common ethnic origin, out of 22 CDA II alleles, 21 (95\%) carried a single substitution (c.325G $>$ A, E109K). This mutation is the single most common SEC23B mutation, identified in $30 \%$ of CDA II patients $[3,10]$. One allele $(\mathrm{H} / 9$; fig. 1$)$ carried a novel missense change, i.e. c. $2129 \mathrm{C}>\mathrm{T}$ (T710M). The fact that this substitution was not found among 214 unaffected alleles strongly suggests that it is a true disease-causing mutation rather than a neutral polymorphism.

Twenty-one out of 22 chromosomes (95.5\%) carrying the CDA II E109K mutation carried the same haplotype (1-5-C-G; fig. 1), while only $31 \%$ of normal control chromosomes were potential carriers of the same haplotype $\left(\mathrm{p}=1.2 \times 10^{-9}\right)$, thus confirming the presence of a founder haplotype. Screening of 204 alleles from healthy Moroccan Jewish subjects identified 1 mutation carrier (approx. $0.5 \%$ ), suggesting that the prevalence of CDA II in this population is 1 in 40,000 . Further analysis of CDA II patients in Israel will reveal the true incidence of the disease in our population.

One of our patients (F/3; fig. 1) carrying the same haplotype was of Moroccan-Algerian descent. Considering 
the close geographic proximity of Morocco and Algeria, we presume his ancestors had a common genetic origin. Furthermore, the E109K mutation has been previously described in various other nationalities, including Turkish, German, Romanian, Italian and Moroccan patients [3, 4, 10]. Future haplotype analysis of the chromosomal background in those patients will suggest whether the mutation appeared independently on several chromosomes or whether some of them originated in a common founder.

Based on the haplotype length and using a computer estimation program, the age of the E109K mutation was estimated to be 2,400 years. This figure is in accordance with historical Jewish migration movements. The Moroccan Jews are descendents of an ancient community that was exiled from the land of Israel, mostly to Babylon, after the destruction of the First Temple in 586 BC. Those who settled in Morocco remained relatively isolated until the 20th century and were characterized by a high rate of consanguineous marriages.

A detailed clinical picture was available for 9 out of 10 patients homozygous for the E109K mutation. The patients were moderately affected; mean hemoglobin was $10.7 \mathrm{~g} / \mathrm{dl}$ (range 9-12.2 g/dl; table 1). None was transfu- sion dependent. Most patients had undergone splenectomy [7]. As previously described, secondary hemochromatosis increased with age [8]. Recently, Iolascon et al. [10] suggested that patients carrying 2 missense mutations tend to be more mildly affected compared to compound heterozygotes for a nonsense and a missense mutation. Our patients, all carrying missense mutations, did indeed have a moderate phenotype; none was transfusion dependent and only 3 patients had required one transfusion each, during the neonatal period (1 patient) and due to intercurrent infections (2 patients).

In summary, the majority of patients with CDA II identified in Israel to date are of Moroccan Jewish descent and carry a common founder SEC23B missense mutation (E109K). This report constitutes the first description of a founder mutation in the SEC23B gene. All patients carried 2 missense mutations and had a nonsevere phenotype.

\section{Acknowledgment}

We are indebted to Dr. Elena Michaelovsky for her valuable help with haplotype determination.

\section{References}

1 Heimpel H, Wendt F: Congenital dyserythropoietic anemia with karyorrhexis and multinuclearity of erythroblasts. Helv Med Acta 1968;34:103-115.

-2 Dgany O, Avidan N, Delaunay J, Krasnov T, Shalmon L, Shalev H, Eidelitz-Markus T, Kapelushnik J, Cattan D, Pariente A, Tulliez M, Cretien A, Schishmanoff PO, Iolascon A, Fibach E, Koren A, Rossler J, Le Merrer M, Yaniv I, Zaizov R, Ben-Asher E, Olender T, Lancet D, Beckmann JS, Tamary H: Congenital dyserythropoietic anemia type I is caused by mutations in condanin-1. Am J Hum Genet 2002;71:1467-1474.

- 3 Schwarz K, Iolascon A, Verissimo F, Trede NS, Horsley W, Chen W, Paw BH, Hopfner KP, Holzmann K, Russo R, Esposito MR, Spano D, De Falco L, Heinrich K, Joggerst B, Rojewski MT, Perotta S, Denecke J, Pannicke U, Delaunay J, Pepperkok R, Heimpel H: Mutations affecting the secretory COPII coat component SEC23B cause congenital dyserythropoietic anemia type II. Nat Genet 2009;41:936-940

-4 Bianchi P, Fermo E, Vercellati C, Boschetti C, Barcellini W, Iurlo A, Marcello AP, Righetti PG, Zanella A: Congenital dyserythropoietic anemia type II (CDAII) is caused by mutations in the $S E C 23 B$ gene. Hum Mutat 2009;30:1292-1298.
5 Lind L, Sanstrom H, Wahlin A, Eriksson M, Nilsson-Sojka B, Sikstrom C, Holmgren G: Localization of the gene for congenital dyserythropoietic anemia type III, CDAN3, to chromosome 15q21-q25. Hum Mol Genet 1995;4:109-112.

-6 Crookston JH, Crookston MC, Burnie KL, Francombe WH, Dacie JV, Davis JA, Lewis SM: Hereditary erythroblastic multinuclearity associated with a positive acidified-serum test: a type of congenital dyserythropoietic anemia. Br J Haematol 1969;17:11-26.

7 Delaunay J: Congenital dyserythropoietic anemias. Orphanet Encyclopedia, October 2003. http://www.orpha.net/data/patho/GB/ uk-CDA.pdf.

-8 Heimpel H, Anselstetter V, Chrobak L, Denecke J, Einsiedler B, Gallmeier K, Griesshammer A, Marquardt T, Janka-Schaub G, Kron M, Kohne E: Congenital dyserythropoietic anemia type II: epidemiology, clinical appearance, and prognosis based on long-term observation. Blood 2003;102: 4576-4581.

9 Gissen P, Maher ER: Cargos and genes: insights into vesicular transport from inherited human disease. J Med Genet 2007;44: 545-555.
10 Iolascon A, Russo R, Esposito MR, Asci R, Piscopo C, Perrotta S, Fénéant-Thibault $M$, Garçon L, Delaunay J: Molecular analysis of 42 patients with congenital dyserythropoietic anemia type II: new mutations in the $S E C 23 B$ gene and a search for a genotypephenotype relationship. Haematologica 2010; 95:708-715

11 Berrebi A, Efrati P: Congenital dyserythropoietic anemia type 2 (HEMPAS) in Jews from Morocco. JAMA 1974;229:24.

12 Efrati P, Berrebi A: Congenital dyserythropoietic anemia type 2: a clinical, morphological and serological study of 7 cases. Hematologica 1976;30:396-398.

13 Rannala B, Reeve JP: High-resolution multipoint linkage-disequilibrium mapping in the context of a human genome sequence. Am J Hum Genet 2001;69:159-178.

14 Reeve JP, Rannala B: DMLE+: Bayesian linkage disequilibrium gene mapping. Bioinformatics 2002;18:894-895.

15 Mor-Cohen R, Zivelin A, Fromovich-Amit Y, Kovalski V, Rosenberg N, Seligsohn U: Age estimates of ancestral mutations causing factor VII deficiency and Dubin-Johnson syndrome in Iranian and Moroccan Jews are consistent with ancient Jewish migrations. Blood Coagul Fibrinolysis 2007;18:139-144. 